\title{
Deoxygenated Hemoglobin
}

National Cancer Institute

\section{Source}

National Cancer Institute. Deoxygenated Hemoglobin. NCI Thesaurus. Code C126121.

Hemoglobin containing a heme group that is not bound to oxygen (O2). This molecule is normally found in the systemic veins following transit through capillaries and release of $\mathrm{O} 2$ into the tissues. Excess deoxyhemoglobin can be associated with hypoxia. 